\title{
CAIO PRADO JÚNIOR E A ATUALIDADE ${ }^{1}$
}

\author{
Igor Zanoni Constant Carneiro Leão*
}

\begin{abstract}
RESUMO: Caio Prado Júnior, ao lado de outros autores fundamentais que pensaram o desenvolvimento capitalista do país, em especial desde o modernismo dos anos trinta, nos deixou como herança uma preocupação com as questões que, embora reelaboradas, estão no cerne da discussão de uma alternativa democrática para os dilemas que hoje enfrentamos: a defesa do conjunto da economia e sociedade brasileiras, pensado no sentido de um país industrializado, integrado e homogêneo socialmente, democrático e soberano, que atenda às necessidades básicas de sua população.
\end{abstract}

PALAVRAS-CHAVE: Caio Prado Junior, desenvolvimento, democracia, economia e sociedade.

\begin{abstract}
Among other important authors who have discussed capitalist development in Brazil - especially since the modernism from the 1930s -, the historian Caio Prado Júnior has bequeathed many questions which are in the center of the discussions about a democratic alternative to the contemporary dilemmas the nation has to face: the defense of the Brazilian economy and society considering the context of an industrialized country, not only socially integrated but also democratic and sovereign, a country which meets the basic needs of its population.
\end{abstract}

KEYWORDS: Caio Prado Junior, development, democracy, economy and society.

* Professor do Departamento de Economia da Universidade Federal do Paraná, Doutor em Economia pelo Instituto de Economia da Unicamp com Pós-doutorado em Ciências Sociais pela Universidade Federal do Paraná. Email: igorzaleao@yahoo.com.br.

${ }^{1}$ Este texto foi desenvolvido como parte das atividades do grupo de pesquisa registrado no diretório de pesquisa do CNPq "Pensamento Social, Intelectuais e Circulação de Ideias" no Departamento de Sociologia da UFPR. 
Este artigo consiste em identificar as principais propostas teóricas e políticas desenvolvidas por Caio Prado Júnior em sua vasta obra de pensador do Brasil, ressaltando sua atualidade no crítico momento da vida nacional. Esta obra se inicia em um diálogo com outros autores centrais no pensamento social brasileiro, e é marcada pelas preocupações de sua gênese. Contudo, durante seu desdobramento, até o final dos anos setenta, ela se estende e complexifica guardando as preocupações e arcabouço ideológio originários, lembrando o adágio de que "os grandes autores sempre se repetem". Assim, é possível perceber a construção de uma matriz teórica centrada no conceito e na proposta política, até hoje derrotada mas essencial ao pensamento democrático, da nação entendida como laços de solidariedade forjados por uma cultura comum.

Uma forma de apresentar alguns temas e elementos centrais na obra de Caio Prado Júnior consiste pois em contrapô-la à de outros autores com obras contemporâneas aos seus primeiros momentos. Em um primeiro plano, o da história econômica, creio que o melhor contraponto a este autor é Roberto C. Simonsen em História Econômica do Brasil (1500/1820), cuja primeira edição é de 1937. Os dois livros mais importantes nessa área, de Caio Prado Júnior, são Formação do Brasil Contemporâneo (1.a edição em 1942) e História Econômica do Brasil (1.a edição em 1945).

Deve-se lembrar, como assinala Afrânio Peixoto, no prefácio ao livro de Simonsen, seu pioneirismo. Ele constitui a primeira tentativa bemsucedida de escrever uma história econômica, em oposição às existentes histórias políticas e administrativas do Brasil. Mais do que isso, a história econômica de Simonsen buscava a "infra-estrutura decisiva e fundamental da história descritiva tradicional", permitindo ver a história da civilização como um todo coeso e não mais uma história do Brasil separada da história da América e do mundo.

Simonsen destaca a importância da história econômica para a compreensão da história política e militar nos tempos modernos, acentuando a pequena importância a ela conferida não apenas nas faculdades superiores do Brasil, mas inclusive na Inglaterra e Estados Unidos. Destaca ainda Simonsen o pequeno interesse dos historiadores 
nacionais pelo tema, ressalvando entretanto alguns, como Varnhagen, Capistrano de Abreu e, sobretudo, Pandiá Calógeras.

O livro de Simonsen vem, pois, preencher diversas lacunas, políticas e acadêmicas. O livro destacará, segundo seu autor, a era colonial, por "ter sido na era colonial que se formou a trama social asseguradora da estrutura unitária do País, buscando clarificar os fatores externos que influenciaram o nosso período embrionário, que tiveram e que continuam a atuar na modelagem da nossa formação econômica" (SIMONSEN, 1978, p. 25). É nesse sentido que Simonsen estudará inicialmente o período de transição para o capitalismo na Europa, enfatizando a revolução comercial como condição prévia ao nascimento da revolução industrial. $\mathrm{Na}$ esteira da revolução comercial formam-se grandes países agrícolas dentro de uma nova divisão do trabalho e são adotadas pelos grandes e emergentes estados nacionais definidas políticas coloniais que atuaram em nosso passado e ainda atuavam, dada a natureza tropical da maior parte da nossa produção.

É pois a partir da situação colonial que se examinará a formação e a atualidade econômica do Brasil, destacando as diferentes condições em que se desenvolve a nossa economia vis-à-vis a das nações que, a partir do Antigo Regime, iniciam sua transformações no sentido de sociedades capitalistas modernas. No Brasil, a colonização teve de recorrer à agricultura, em um meio pouco atraente ao elemento europeu e adstrito a produtos tropicais, trazendo os portugueses uma grande massa de população africana que se reuniu à primitiva população autóctone.

A partir daí Simonsen organiza seus temas, sumariando os primórdios da invasão portuguesa, bem como da Espanha, em sua relação com a expansão comercial e o domínio e aproveitamento dos novos territórios, ultramarinos. Passa em seguida à forma inicial de aproveitamento das terras de Santa Cruz num contexto de expansão comercial da Índia e do Oriente e examina as políticas coloniais criadas para o Brasil como ponto de partida para a economia do açúcar. O ciclo do açúcar, na gênese de uma colônia marcada pela grande exploração de produtos tropicais com mão de obra servil, primeiro indígena e logo africana; a expansão da pecuária e sua importância para a unidade do Brasil; o ciclo da mineração, 
relacionado com a expansão paulista para o interior; os fundamentos da ocupação do Amazonas; o balanço do comércio da era colonial e os primeiros momentos de vida autônoma após a vinda de D. João VI ao Brasil, são os temas levantados de forma a compor uma agenda detalhada e complexa de problemas para os historiadores futuros da sociedade e economia brasileiras.

Não é por outro motivo que os pontos levantados por Simonsen reaparecerão sob outro tratamento seja em Caio Prado Júnior seja, mais tarde, em Celso Furtado, com a Formação Econômica do Brasil (1 $1^{\mathrm{a}}$ edição em 1955). Em Caio Prado Júnior, especificamente, as preocupações anteriores são retomadas a partir de uma visão do Brasil característica de toda a sua obra: a visão de um país que transita da condição colonial para a de independente e autônoma, transição ainda incompleta, mas cujo desenrolar é o foco contínuo de Caio Prado Jr. Este reorganiza, portanto, o material de Simonsen, soma elementos, compõe com sua obra historiográfica um painel montado a partir de um ponto: a construção da nação. Esta construção passa a um primeiro plano, no qual diversos aspectos da vida da colônia e depois do país independente são elaborados, desde a vida material à vida social e política, da formação étnica à administração portuguesa. Estes aspectos são pois examinados a partir da gênese da colônia e do processo de passagem para nação. A revolução brasileira será precisamente uma proposta política capaz de conferir ao país o estatuto de nação, proposta montada a partir das singularidades que caracterizam a formação do país.

Dentro desse plano, seja a Formação do Brasil Contemporâneo, seja a História Econômica do Brasil, compõem, juntamente com outras obras, como Diretrizes para uma Política Econômica; História e Desenvolvimento; A Questão Agrária; e A Revolução Brasileira, um conjunto de problemas e temas centrais que é insistentemente reposto a partir de vários ângulos. Tanto mais que Caio Prado Jr. não se vê como um mero historiador econômico, mas como o historiador que procura dar conta dessa questão abrangente e complexa que é a formação de uma nação. Isto explica o sucinto comentário de Caio Prado Jr. à História de Simonsen na bibliografia da História Econômica do Brasil: "trabalho sobretudo informativo". É muito pouco, pois Simonsen 
é pioneiro que Caio Prado Jr. retoma, mas se explica pelos contornos distintos do livro de Simonsen na sua visão ideológica.

Caio Prado Jr. é um pensador mais original e complexo da constituição da nação, seja comentando o campo brasileiro, seja trabalhando a questão do capital estrangeiro e assim por diante. A nação é entendida como objetivo a ser alcançado politicamente ao mesmo tempo que se forma por meio de rupturas com a ordem colonial, através da independência, a abolição, a república, a industrialização e outras que criariam na história nexos de solidariedade específicos rumo a uma sociedade marcada pelo atendimento dos interesses do conjunto da população que aqui vive e trabalha, rompendo com seu passado colonial visto de modo bastante crítico. Simonsen, por sua vez, coloca-se, como autor e ator político e empresarial, em um marco positivista, buscando o ideal da ordem e do progresso, bem como percebendo uma continuidade entre a colônia e o Brasil independente, na medida em que a primeira fornece ao segundo os elementos primeiros à sua entrada na civilização moderna. Esta transição se completaria, via conciliação de classes, a doutrina social da Igreja e a atuação privilegiada do Estado no planejamento econômico, através da constituição de um capitalismo autônomo, no contexto dos modernos países civilizados. Há pois entre ambos os autores proximidade e distância teóricas e políticas.

A riqueza do trabalho de Caio Prado Jr. permite sua contraposição não apenas a Roberto Simonsen, mas ao conjunto de autores que, sobretudo nos anos trinta, elaboram retratos do Brasil, buscando captar o sentido da nossa evolução como país, desde o próprio Retrato do Brasil, de Paulo Prado, primo de Caio, cuja primeira edição é de 1928, até autores como Oliveira Vianna, Gilberto Freyre, Sérgio Buarque de Holanda e outros de notória importância. Embora esses autores assumam posições políticas e ideológicas diversas, têm uma problemática comum: a passagem de uma sociedade marcada pelo seu passado colonial e, portanto, pela incoesão social e o personalismo; a outra, capitalista, dominada por laços de solidariedade e, ao mesmo tempo, a passagem de um Estado patrimonial ou oligárquico a um Estado burocrático e moderno. Esses temas não são excluídos por Caio Prado Júnior, principalmente em sua obra-prima, 
a Formação do Brasil Contemporâneo. Em seus textos encontram-se os temas da heterogeneidade social e econômica, a distorção do liberalismo, a ineficácia da administração pública e outros.

Ainda que Caio Prado Júnior recuse intitular a revolução brasileira como democrática ou popular, ou outros adjetivos quaisquer, para ressaltar suas raízes autóctones e suas particularidades, é evidente que ele se move no âmbito de uma recusa ao liberalismo (como, aliás, Roberto Simonsen), da busca de uma transição a um capitalismo marcado pela coesão social, a cessação de miséria, a industrialização calçada no Estado e no capital nacional, assumindo pois uma postura política bastante clara. Nesse âmbito é que Caio Prado Júnior é um autor que deve ser colocado em face dos novos retratos do Brasil iniciados nos anos trinta e seus autores.

O nacionalismo de Caio Prado Júnior, um dos traços característicos de sua obra, já aparece naqueles retratos, a começar por Paulo Prado, com seu Retrato do Brasil, Sérgio Buarque de Holanda ou por autores anteriores, como Oliveira Vianna. Situar Caio Prado no seu tempo exige pois que se conheça algo desses autores, com os quais Caio Prado Júnior sempre interagiu. Retrato do Brasil, Raízes do Brasil e os livros de Oliveira Vianna remetem à mesma questão - a transição do capitalismo no Brasil - projetando imagens ou retratos do País até certo ponto intercambiáveis. Apesar disso, apresentam propostas políticas ou "vias de transição" a uma sociedade moderna distintas.

Nesses livros, a transição, assimilada explicitamente a um processo de revolução burguesa, também é vista como a passagem de uma sociedade marcada pela incoesão social e o personalismo a outra dominada por laços de solidariedade social e, ao mesmo tempo, como a passagem de um Estado patrimonial, ou oligárquico, a um Estado burocrático ou moderno. Da mesma forma, esses textos se tocam ao examinarem as atitudes políticas predominantes. Assim, o povo, mesmo com o avanço da urbanização, mantém valores e práticas políticas moldados no domínio rural. As elites, entendidas como "quadros dirigentes", conservarão na República um caráter aristocrático, distanciando-se da realidade nacional ao adotarem instituições do liberalismo europeu e norte-americano. 
O liberalismo, no Brasil, conflitará com as formas da vida social, traduzindo-se na distorção das instituições liberais clássicas européias. Em consequência, gera-se uma situação de crise, suficiente para colocar em risco a coesão nacional. Nesse quadro, torna-se necessária uma revolução que, readequando as instituições estatais à morfologia da sociedade, forneça a esta a sua coesão nacional. A revolução é condição indispensável para a continuidade do processo de urbanização ou de desenvolvimento capitalista, pois a crise do Estado liberal se manifesta em ineficiência do aparelho de Estado, incapaz de expressar mais que solicitações contraditórias das distintas oligarquias.

Evidentemente, este esquema ignora nuances imponentes de formulação entre os livros citados, mas é válido como aproximação a todos eles. Os livros divergem, entretanto, na sua proposta de reforma política. Raízes do Brasil, de Sérgio Buarque de Holanda, embora não ignore que a transição e a superação da crise possam ser realizadas através de uma experiência autoritária, indaga pela possibilidade de uma "verdadeira revolução", a um tempo democrática, nacional e popular. Oliveira Vianna e Paulo Prado inscrevem-se na tradição nacionalista-autoritária. Entre ambos há, entretanto, uma diferença importante de formulação, uma vez que Oliveira Vianna, propondo um Executivo forte e centralizado, procura ligar governo e povo pelo funcionamento das corporações de base econômica e cultural. Dessa maneira, segundo imagina, seria possível criar uma administração pública eficiente e apolítica. A proposta de Oliveira Vianna encaminha um Estado agente da modernização econômica e pedagogo do povo e da elite, que ganhariam, pela participação na administração pública, consciência nacional.

Sérgio Buarque, em contrapartida, não consegue vislumbrar suportes sociais para sua proposta, que perde, dessa forma, muito de sua força. Aparentemente, Oliveira Vianna está na sua dianteira no que se refere à questão de como superar as atitudes insolidárias tradicionais. Entretanto, há neste momento um problema em sua formulação, pois em Oliveira Vianna as corporações "nascem e morrem" no Estado, que as organiza de cima para baixo. 
Aqui começam a surgir novas distinções importantes entre esses autores. Em Oliveira Vianna, coesão nacional significa supressão das possibilidades de conflito social. A ação das corporações será, portanto, concebida de forma a harmonizar relações de classe, para o que é essencial que o Estado defina e regule as formas de participação na administração, escolhendo, além disso, suas próprias fontes de opinião pública. A revolução buscará um desdobramento sem rupturas, como se o Estado e a sociedade pudessem conservar-se estáticos.

Em Sérgio Buarque, ao contrário, a concepção de revolução burguesa associa-se a um conjunto de rupturas, e a introdução dos novos tempos parece depender de instituições estatais que permitam seu desdobramento político, reequilibrando vida social e instituições políticas. O sentido dos termos "coesão", ou "harmonia", por ele utilizados, ganha desta forma uma conotação distinta, referida a um projeto de hegemonia de camadas algo vagamente denominadas populares e urbanas.

Este projeto, constata Sérgio Buarque, não pode se basear no liberalismo clássico e nos partidos tradicionais, "importações" inadequadas à "nossa realidade". Não consegue, entretanto, delinear as instituições adequadas ou a forma de agendá-las. Por sua vez, Oliveira Vianna, tanto quanto Paulo Prado, tampouco esclarece quais são os suportes de sua própria proposta, uma vez que permanece obscura a natureza de seu Estado Autoritário/Corporativo. Que Estado é esse, aparentemente autônomo ou exterior à sociedade, diante de um povo e uma elite marcados pela inépcia política?

Centrando-nos em Paulo Prado, seu livro Retrato do Brasil ganha bastante com a leitura prévia de Raíres do Brasil. O livro de Sérgio Buarque retoma do primeiro sua questão básica - a passagem de uma sociedade patriarcalista e de um Estado patrimonial a uma sociedade e um Estado modernos no Brasil, e os temas mais importantes ligados a essa questão, bem como os temas da anarquia da vida nacional, da relação capitalismodemocracia e da revolução burguesa.

Os dois livros coincidem em diversas observações e conclusões sobre esses temas. A cobiça e a luxúria que, segundo Paulo Prado, presidem à colonização do Brasil, terão paralelo na ética da aventura e no desleixo, 
de Raízes do Brasil, enquanto fontes da insolidariedade social. Em ambos os autores, esses conceitos apreendem a dominação do capital mercantil na colônia, associando-se à escravidão, ao baixo grau de desenvolvimento da divisão social do trabalho e à ética e moralidade senhoriais.

Da mesma forma, o desencanto frente à realidade, fruto do choque entre a mentalidade senhorial e a urbanização, segundo Sérgio Buarque, constitui-se num eco da "tristeza brasileira" que subintitula Retrato do Brasil. A mesma tristeza, ou desencanto, explicará nos dois livros o alheamento das elites, seu bacharelismo ou, ainda, seu romantismo. A anarquia da vida social e o bacharelismo e conservadorismo das elites darão funcionamento próprio às instituições liberais, concluindo ambos os autores pela inviabilidade do liberalismo no Brasil.

Entretanto, Raízes do Brasil leva adiante a análise de Retrato do Brasil, como se observa, por exemplo, através do conceito de revolução empregado nos dois livros. A ideia de revolução como simples assalto ao poder transforma-se em Sérgio Buarque na ideia de um conjunto de rupturas, com dimensões e momentos distintos, na direção do capitalismo. A transição ao capitalismo surge dessa forma como um movimento complexo, enquanto Retrato do Brasil projeta antes a imagem de uma sociedade e de um Estado quase imóveis, à espera da revolução capaz de introduzir os novos tempos.

Em boa medida por essa distinção, Sérgio Buarque não descrê na possibilidade de a revolução desaguar numa democracia adaptada às formas específicas da vida social e capaz de conferir à transição um caráter nacional e popular. Paulo Prado, ao contrário, aponta para uma vida estatista ou autoritária e também nacional. Todavia, como apontado, Buarque não consegue apontar os fundamentos sociais que sustentariam uma via democrática de transição, confiando nas influências da própria urbanização. Raízes do Brasil torna-se, assim, paradoxal, justapondo uma proposta democrática a uma virtual demonstração de sua impossibilidade.

Paulo Prado tampouco explicita os suportes de sua revolução que, distinguindo-se de um movimento caudilhista, parece depender de indivíduos com consciência da nação, isto é, de sua unidade (territorial) e do que é necessário para mantê-la (a redefinição de uma política de 
desenvolvimento capitalista). A proposta, entretanto, é obscura. Essas observações indicam a superficialidade da aproximação entre Paulo Prado e Sérgio Buarque estabelecida por alguns críticos. Não bastassem as diferentes propostas políticas, Sérgio Buarque parece ter tomado Retrato do Brasil como um ponto de partida, desenvolvendo e precisando conceitos e uma análise que permitem reler Paulo Prado.

Neste ponto se impõe o esboço da matriz teórica de Caio Prado Júnior. Seu ponto de partida é o conceito de nação, construído a partir das noções de soberania, democracia, igualdade social, homogeneidade social e industrialização. A nação, no autor, é tanto um valor e, logo, uma proposta política, quanto uma categoria analítica. $\mathrm{O}$ exame do autor começa pois pela análise dos conceitos básicos, o de economia colonial, que é o ponto de partida do processo de formação do capitalismo brasileiro, e o de economia nacional, que é seu ponto, ainda não totalmente atingido, de chegada. A economia nacional é conceito construído observando-se o capitalismo desenvolvido, remetendo às noções de estrutura industrial integrada, na qual produção e consumo se alimentam mutuamente, e de um organismo produtivo voltado para o atendimento das necessidades fundamentais da população que trabalha e vive no país. Por seu lado, a economia colonial é construída conceitualmente a partir da forma de inserção da colônia brasileira nas primeiras etapas do capitalismo mundial, como estrutura produtiva voltada para o atendimento de mercados exteriores e calçada na grande lavoura monocultora e no trabalho servil. $\mathrm{O}$ autor destaca, com isso, a especificidade da formação do nosso capitalismo, em oposição à visão da III Internacional, que postulava um desenvolvimento das nações sul-americanas por etapas que repetiriam a sucessão dos modos de produção observada na história dos países europeus. Entre a economia colonial e a economia nacional media o desenvolvimento do capitalismo no sentido da constituição da nação tal como entendida pelo autor, o que leva a análise para um plano complexamente construído, nos níveis político, social e econômico.

O autor propõe nessa trajetória uma periodização que articula um momento externo - o desenvolvimento do capitalismo internacional em suas etapas: o capitalismo mercantil, o capitalismo concorrencial 
e o imperialismo - a um momento interno, revelado por marcas como a independência política, a cessação do tráfico e a abolição, a república e a crise da economia capitalista exportadora do café. Nesse sentido, a dinâmica do desenvolvimento é entendida como uma análise da totalidade, feita exemplarmente em Formação do Brasil Contemporâneo e, mais limitadamente, em História Econômica do Brasil. Nesse contexto, Caio Prado Júnior faz um balanço da obra colonizadora na virada do século XVIII para o XIX e acompanha as articulações sucessivas e contraditórias que impulsionam e limitam a configuração da nação, entre o momento externo e o momento interno, deixando claro como a crescente complexidade do processo produtivo, a progressiva homogeneização social e o crescimento de um mercado interno potencial conduzem inexoravelmente ao desenho da nação e à superação dos remanescentes coloniais, inclusive porque estes são incompatíveis com o equacionamento de problemas na balança de pagamentos e de uma organização financeira sólida no país.

O conceito de revolução do autor é o de rupturas com os remanescentes da economia colonial nascida nas circunstâncias e especificidades do desenvolvimento brasileiro, e aponta para a consecução final do projeto nacional, partindo do estádio já atingido por esse mesmo desenvolvimento. Por isso, o programa da revolução apontará para a superação dos resíduos escravistas nas relações de trabalho no campo, pela reforma agrária destinada a ampliar o mercado interno e supri-lo em gêneros de consumo interno, pela luta anti-imperialista, que passa pelo controle estatal do comércio externo e pelo controle das remessas de lucros para o exterior, bem como por uma rigorosa intervenção estatal no livre curso da iniciativa privada, como forma de integrar e dar bases sólidas à indústria. Os suportes dessa revolução serão as classes populares no campo e na cidade, uma vez que as classes burguesas estão profundamente ligadas à do imperialismo no país, sem que isso signifique uma proposta de ruptura com o capitalismo, o que para Caio Prado Júnior não está na agenda política, mas sim um relacionamento entre classes e segmentos sociais voltados para uma solidariedade orgânica ainda que baseada em meios mercantis. 
Deve-se fazer aqui duas observações. A primeira é que Caio Prado Júnior procede a uma recuperação do passado brasileiro, dentro da sua ótica teórica, utilizando sobretudo suas ferramentas de historiador. Não possui, ao mesmo tempo, um aparato analítico baseado na teoria econômica, ao contrário, por exemplo, de Celso Furtado. A obra deste último, claramente, e sem que ele mesmo dê os devidos créditos, se inspira em Caio Prado Júnior, seja em seus conceitos fundamentais, seja em sua periodização do desenvolvimento, mas Furtado possui um aparato analítico centrado em conceitos criados por ele através de seu método histórico-estrutural, como a noção de fluxo de renda ou a de subdesenvolvimento, que permitem dar uma explicação renovada a problemas como o desemprego, a desigualdade social, as disparidades regionais e os empecilhos ao desenvolvimento. Isto tornará a obra de Furtado mais conhecida e difundida, dados os nossos crônicos impasses relativos ao desenvolvimento econômico, tornando-o mesmo o autor, segundo Maria da Conceição Tavares, o "santo das esquerdas". Todavia, intelectual seminal e original, autodidata, Caio Prado Júnior desenvolve uma contribuição que se dá antes dos primeiros trabalhos da Cepal e de outros que nele se inspiram, como o próprio Furtado e historiadores e economistas ligados à escola de Campinas, dele todos tributários.

Entretanto, a proposta de Caio Prado Júnior, a conclusão do processo de constituição da nação nos moldes em que delineou, é muito mais uma proposta (e uma derrota) política que uma visão da dinâmica sócio-econômica. Nesse sentido, permanecem na agenda preocupações que ele levantou, como a da dependência externa, e sobretudo a construção de uma sociedade que insira sua população no teor de vida material e cultural próprio das populações dos países desenvolvidos. E aí se coloca a questão dos direitos trabalhistas no campo, a da reforma agrária, a do papel do Estado e do planejamento e outras que ele, historiador, levantou, e gerações de economistas e homens de Estado maltrataram ou ignoraram. Estamos aí já no terreno da sua atualidade.

Exponho a seguir algumas reflexões sobre a atualidade de Caio Prado Júnior no que se refere aos impasses atuais do nosso desenvolvimento. Em primeiro lugar, é consensual que, diante da problemática desse 
desenvolvimento tal como ela se apresentava nos anos mais fecundos da produção teórica do autor, este soube reunir numa visão abrangente os aspectos principais da economia e sociedade brasileiras na ótica de sua proposta política e analítica. A consecução de uma visão com grau semelhante de abrangência do período complexo iniciado no regime militar e desdobrado de modo radical nos anos noventa, bem como suas múltiplas implicações, é tarefa que se impõe aos nossos atuais analistas.

Sem tentar fazer um diagnóstico da crise brasileira atual, em suas várias faces, tarefa de que muitos se incumbiram, lembremos que ela tem um claro componente interno, expresso por exemplo na chamada "privatização do Estado" e sua decorrente crise fiscal e financeira, bem como no nó górdio da industrialização brasileira, o de um padrão adequado de financiamento do investimento. Todavia, ela apresenta componentes derivados da reestruturação produtiva dos países centrais e sua "modernização conservadora", com reflexos diretos sobre o tecido produtivo e social dos países do segundo e terceiro mundos e, logo, também sobre a economia e a sociedade brasileiras.

Essa combinação de elementos internos e externos, que expressa as dificuldades e inspira alternativas políticas do desenvolvimento do país, tem se traduzido numa virtual estrada para a desindustrialização e retorno a uma condição de subdesenvolvimento, na medida em que os setores mais importantes do ponto de vista das modernas estruturas industriais atrasam-se fortemente em termos tecnológicos e produtivos ou sequer chegam a se instalar, observando-se o mesmo atraso em setores montados há muito no Brasil, como o têxtil. A liberalização progressiva das importações, os descaminhos da política tecnológica no país, a valorização do câmbio provocada em última instância pelo poder financeiro global, dentre outros fatores, agravaram esse quadro, problematizando o desenvolvimento de setores novos e dos já instalados, minando o espaço das empresas nacionais, já historicamente frágil. A queda do investimento na economia, ligada em grande medida ao desaparecimento de empresas estatais nos anos noventa, colaborou para o atraso tecnológico, assim como a forte concentração do investimento das empresas transnacionais nos países centrais. 
Uma modernização parcial observa-se apenas nas maiores empresas, em geral estrangeiras, sem grande aumento de capacidade produtiva, levando todo esse contexto a uma crescente heterogeneidade produtiva da economia bem como a uma nova forma de heterogeneidade social, uma vez que o nível de empregos cresce ligado a uma nova classe classe trabalhadora de remunerações baixas e ocupações marcadas pela precariedade, ao mesmo tempo que a antiga classe média se deteriora e ascende uma camada de novos ricos dependentes das convenções oscilantes do mercado, da qual foi herói Eike Batista. Uma inserção passiva na economia mundial, mantida, a rigor, desde o governo Collor, tem substituído esforços coerentes no sentido da retomada da industrialização e suas implicações sociais. A esse esgarçamento do tecido produtivo tem também correspondido uma crescente fragmentação da solidariedade entre as diversas regiões do país que se centrava no dinamismo industrial e do investimento público e privado.

Fica clara, observando a cena brasileira, uma acelerada corrida para o subdesenvolvimento, que a proposta neoliberal de restringir o papel do Estado a assegurador da estabilização monetária e de uma tímida busca de combate à pobreza e exclusão não pode deter. De fato, como assegurar estabilidade à moeda se a âncora principal desta é a própria produção, e o dinamismo desta, numa economia complexa e diversificada como a nossa, não pode se basear em elementos como a inserção passiva ou via reprimarização exportadora no mercado internacional, cujo crescimento, aliás, é baixo, e centrado nos países mais desenvolvidos? Os chamados emergentes, cujo exemplo notório é a China, apresentam mais incógnitas que soluções no sentido da construção de sociedades democráticas e soberanas, sustentáveis em trermos ambientais e matrizes de uma cultura material original, nos quadros do dinheiro e do poder mundial. Como assegurar equidade social com políticas sociais minadas pelo assédio do poder financeiro aos recursos públicos, deixando de lado intervenções mais decisivas do Estado em âmbitos como a distribuição da renda , a elevação dos salários, a reforma da estrutura agrária, o enfrentamento da hipertrofia política e econômica do setor bancário e os ganhos imobiliários ligados à nossa rápida e desordenada metropolização? Como buscar, dessa forma, 
elementos legitimadores da ordem política, como a busca da igualdade e homogeneidade sociais e perspectivas de ascensão social durável numa economia dinâmica? Como buscar tudo isto sem elementos que reportem a uma revitalização do papel do Estado em seu controle sobre a iniciativa privada, papel planejador em níveis nacional e regional, buscando integrar o tecido produtivo e o tecido de relações sociais e políticas, numa palavra, sem objetivar a consecução da nação?

Nesse sentido, creio que, quaisquer que sejam as críticas que eventualmente se possam fazer à matriz teórica de Caio Prado Júnior, ele é, ao lado de outros autores fundamentais que pensaram o desenvolvimento capitalista do país, alguns dos quais examinados acima neste artigo, um pensador que nos deixou como herança uma preocupação com as questões que, embora reelaboradas, estão no cerne da discussão de uma alternativa democrática para os dilemas que hoje enfrentamos: a defesa do conjunto da economia e sociedade brasileiras, pensado no sentido de um país industrializado, integrado e homogêneo socialmente, democrático e soberano, que atenda às necessidades básicas de sua população. Portanto, um país em que sua condição periférica seja ativamente questionada, mobilizando para isso o Estado como a "força concentrada da sociedade". Um país que, se não pode prescindir do capital estrangeiro para o seu desenvolvimento, o que seria inimaginável, possa negociar com ele na medida em que organiza seu espaço interno num sentido precisamente oposto ao do pensamento neoliberal, isto é, como "capitalismo organizado". Assim, fica claro que Caio Prado Júnior é um pensador para os nossos dias, tanto para enterdermos a trajetória histórica brasileira, como para fornecer pistas acerca do debate sobre a crise que vivemos, se quisermos uma sociedade orientada pelos valores básicos que ele sempre defendeu. Além disso, Caio Prado Júnior nos deixa o problema de quais suportes políticos mobilizar para as transformações de que tanto necessitamos, dada a própria diferenciação observada hoje na sociedade brasileira, e que tem tido até agora, após tantos anos de crise, um papel tão avesso a mudanças. 


\section{BIBLIOGRAFIA}

FURTADO, Celso. Formacão econômica do Brasil. 12. ed. rev. São Paulo: Ed. Nacional, 1974.

HOLANDA, Sérgio Buarque de. Raízes do Brasil. 7 ed. Rio de Janeiro: J. Olympio, 1973.

MELLO, Manuel Cardoso de. Conseqüências do neoliberalismo. Economia e Sociedade, Campinas: UNICAMP/IE, n. 1, ago. 1992.

PRADO JÚNIOR, Caio. A questão agrária. São Paulo: Brasiliense, 1979. . A revolução brasileira. 5 ed. São Paulo: Brasiliense, 1979. . Diretrizes para uma politica econômica brasileira. São Paulo: Gráfica Urupês, 1954.

. Evolução política do Brasil. 2 ed. São Paulo: Brasiliense, 1947.

. Formação do Brasil contemporâneo. 20 ed. São Paulo: Brasiliense, 1987.

- História e desenvolvimento. São Paulo: Brasiliense, 1972.

- História econômica do Brasil. São Paulo: Círculo do Livro, s. d.

. História. Org. por Francisco Iglesias. São Paulo: Ática, 1982. (Coleção grandes cientistas sociais, 26)

PRADO, Paulo. Retrato do Brasil: ensaio sobre a tristeza brasileira. 2. ed. São Paulo, IBRASA: INL, 1981.

SIMONSEN, Roberto C. História econômica do Brasil (1500/1820). 8 ed. São Paulo: Ed. Nacional, 1978.

VIANNA, Oliveira. Populações meridionais do Brasil. Rio de Janeiro: Paz e Terra, 1973.

VIEIRA, Evaldo. Autoritarismo e corporativismo no Brasil. 2 ed. São Paulo: Cortez, 1987. 